\title{
A FORMAÇÃO DE GRADUAÇÃO EM SERVIÇO SOCIAL E AS EXPRESSÕES DE APROPRIAÇÃO DA TEORIA SOCIAL CRÍTICA
}

\author{
Amanda Leite Ribeiro' \\ Cleomar Campos da Fonseca²
}

Resumo: Este artigo trata das expressões de apropriação da Teoria Social Crítica, de base marxiana, junto aos conteúdos programáticos de disciplinas voltadas para a formação teórico-filosófica dos discentes do curso de graduação em Serviço Social da UEPB. O estudo envolveu um levantamento bibliográfico e documental. As fontes secundárias foram os planos de curso das referidas disciplinas. As aproximações conclusivas indicam que a direção social (e também teórica) orientadora do Projeto de Formação de 1996, não está plenamente fortalecida por conteúdos responsáveis pela abordagem das grandes linhas de pensamento da modernidade, dentre elas, a Teoria Social Crítica, em seu sentido ontológico. Trata-se de uma tendência que guarda relação com o tensionamento - teórico, político, ético e cultural - que vem permeando o Serviço Social brasileiro. Neste sentido, a profissão tem convivido com expressões ideoculturais que vão desde posturas mais voltadas ao trato subjetivista do real a posturas que se esforçam em buscar o sentido das coisas em sua raiz, relacionando aparência e essência como expressões de uma totalidade social.

Palavras-chave: Teoria social crítica; Serviço Social; Formação profissional; Diretrizes curriculares; Direção social.

${ }^{1}$ Curso de Graduação em Serviço Social/Universidade Estadual da Paraíba, Brasil. E-mail: amandha.leite@gmail.com.

${ }^{2}$ Curso de Serviço Social/Departamento de Serviço Social/Universidade Estadual da Paraíba, Brasil. E-mail: cleofonseca11@yahoo.com.br. 